\title{
To Feed or Not to Feed? During Hemodialysis Session
}

\author{
(D) Șennur Köse ${ }^{1}$, (D) Ender Hür², (D) Hüseyin Çelik³ , (D Gökhan Atay4, (D) Bünyamin Altundal5, (D) Soner Duman6 \\ 1 University of Health Sciences Turkey, İstanbul Training and Research Hospital, Clinic of Nephrology, İstanbul, Turkey \\ 2Manisa Merkezefendi State Hospital, Clinic of Nephrology, Manisa, Turkey \\ ${ }^{3}$ Acıbadem Bursa Hospital, Clinic of Nephrology, Bursa, Turkey \\ ${ }^{4}$ Ege University Faculty of Medicine, Department of Internal Diseases, İzmir, Turkey \\ 5Zonguldak Can Dialysis Centers, Zonguldak, Turkey \\ ${ }^{6}$ Ege University Faculty of Medicine, Department of Internal Medicine, İzmir, Turkey
}

\section{ABSTRACT}

Introduction: Patients undergoing hemodialysis (HD) like to eat during HD sessions. To prevent coronavirus infection, health authorities recommended restriction of taking food and fluids. In this multicenter retrospective chart review study, we aimed to confirm the relationship between oral intake and intradialytic complications using the date before and after the restriction in a relatively large HD population.

Methods: Data of a total of 190 (47\% female) patients with prevalent HD during the 3 months before and 3 months after the restriction of oral intake during HD session were collected. In patients who received HD three times a week, data on blood biochemicals and clinical parameters taken routinely at the first week of each month were recorded from the dialysis session files. Differences between the means for both periods were evaluated using the $\chi^{2}$ test for categorical variables and Student's t-test for continuous variables; $\mathrm{p}<0.05$ was considered significant between groups.

Results: The mean age was $66 \pm 11.3$ (23-91) years. Of the patients, $53 \%$ had diabetes mellitus, receiving HD treatment for $65.6 \pm 55.7$ months. Rates of intradialytic hypotension (IDH) and muscle cramps decreased significantly $(0.075 \%$ vs $0.043 \%, p<0.001 ; 0.016 \%$ vs $0.008 \%, p<0.05$, respectively), whereas no changes in the hypoglycemia rate were noted.

Conclusion: IDH and muscle cramps mostly attributed to splanchnic vasodilation-related digestion may be prevented by restriction of food intake during HD sessions.

Keywords: Intradialytic hypotension, hemodialysis, muscle cramps

\section{Introduction}

Patients undergoing hemodialysis (HD) may encounter problems during the intradialytic period. Although some problems are preventable or mitigable, they continue to pose significant challenges to the quality of life of patients on HD. Intradialytic hypotension (IDH) is an upsetting condition mostly accompanied by nausea, vomiting, and muscle cramps during HD sessions. IDH has varied definitions, as there is no ideal blood pressure measurement during the session. Increased mortality was associated with intradialytic systolic blood pressure (SBP) $<90 \mathrm{mmHg}$, whereas the K-DOQI guideline defines it as a drop of SBP $>20 \mathrm{mmHg}$ with accompanying symptoms (1). Increased cardiovascular mortality, loss of residual renal function, vascular access thrombosis, and dialysis insufficiency, which are all related to IDH, are important $(2,3)$.

In dialysis sessions, the prevalence of IDH was $11.6 \%$ if the threshold of SBP $<90 \mathrm{mmHg}$ is accepted for the diagnosis and $10.1 \%$ when it is defined as a $>20 \mathrm{mmHg}$ decrease in SBP in addition to clinical findings and interventions of position and hypertonic solutions (4).

In the normal population, post-prandial hypotension (PPH) has not been clarified yet. According to some recent theories, $\mathrm{PPH}$ may be secondary to a postprandial increase in the levels of vasodilatory polypeptide incretins (5) and an insufficient sympathetic response (6). Another possibility is the attenuation of the arterial baroreflex, especially in the elderly (7).

During feeding, increased splanchnic blood pooling (8) and changes in the hemodynamic response to gastric distension (9) may probably lead to hypotension.

Generally, patients on maintenance HD are allowed to eat during the session. To prevent the spread of coronavirus infection, food, and fluid intake has been restricted by health authorities in our country. In this retrospective chart review study, we aimed to confirm the relationship 
between oral intake and intradialytic complications using data before and after the restriction in a relatively large HD population.

\section{Methods}

In this descriptive chart review study, patients aged $>18$ years with end-stage renal disease undergoing thrice-weekly maintenance HD were enrolled retrospectively. In total, 190 (of 47\% female) patients with prevalent HD every first week of three consecutive HD runs of 3 months before and after restriction of oral intake (dialysate $\mathrm{iCa}=1.25 \mathrm{mmol} / \mathrm{L}$ ) were noted from the dialysis session records. The restriction of oral intake was implemented in March 2021; thus, months from December 2020 to February 2021 were taken as the 3 months before the restriction, and the months from March to May 2021 were taken as the 3 months after the restriction. The exclusion criteria were as follows: presence of a pacemaker or defibrillator, amputation, serious life-threatening comorbid situations (e.g., malignancies), uncontrollable infection, and end-stage cardiac, pulmonary, and hepatic diseases.

Intradialytic complications mainly related to hemodynamic changes (i.e., hypotension), muscle cramps, nausea, vomiting, and dizziness are common among patients with HD. An IDH episode is defined as the difference in pre-HD SBP and minimum SBP during HD of $>20$ $\mathrm{mmHg}$ and symptoms of cramping, nausea vomiting, headache, and light-headedness, which requires fluid intervention (administration of intravenous hypertonic glucose or saline solution to increase blood pressure) (10). Patients in our Hemodialysis Centers were given a meal during each HD session, usually 30-90 min after the start of each session. Patients were served breakfast (tea, bread, cheese, olive, honey, and boiled egg) during the morning session (8-12 h) and cooked meals (soup, poultry, pasta, rice, and meat with vegetables) during the afternoon (13$17 \mathrm{~h})$ and evening (18-22 h) sessions.

Epidemiological data (such as age, sex, presence of diabetes, HD time, frequency and duration of dialysis, dry weight, dialysate calcium, and sodium) in the charts were recorded for each patient. Biochemical tests for hemoglobin, urea, creatinine, potassium, sodium, proteins, albumin, calcium, phosphorus, C-reactive protein (CRP), and parathyroid hormone were performed mid-week of every first week of three consecutive HD runs of the 3 months before and after restriction of oral intake. Kt/V and urea reduction ratio were calculated during this session. All patients were dialyzed on Gambro AK95 machines with bicarbonate dialysis and polysulfone membrane.

The approval form the University of Health Sciences Turkey, İstanbul Training and Research Hospital Local Ethics Committee was obtained (approval number: 2998, date: 24.12.2021). Informed consent was obtained from patients for the use of clinical information and results.

\section{Statistical Analysis}

Statistical analysis was performed by using SPSS 25.0 (IBM Corp., Armonk, NY, USA) program. Categorical variables are presented as number and percentage (\%) and quantitative variables as mean \pm standard deviation.
The Levene test was used to test for the normality of variables before and after restriction of oral intake. Categorical variables (intradialytic complications such as hypotension and muscle cramp) were compared using the $\chi^{2}$ test. For comparison of quantitative variables, paired Student's t-test was used for those with normal distribution, and the Wilcoxon sign test was used for those who were not normally distributed. Statistically, $p<0.05$ was considered significant.

\section{Results}

The mean age of the patients was $66 \pm 11.3$ (23-91) years. Of the patients, $53 \%$ had diabetes mellitus, with an HD treatment duration of $65.6 \pm 55.7$ months.

The dry weight decreased from $69.6 \pm 14.66$ to $69.3 \pm 14.52 \mathrm{~kg}(p<0.01)$, and the post-HD body weight decreased from $70.0 \pm 14.77$ to $69.7 \pm 14.74$ $\mathrm{kg}(\mathrm{p}<0.05)$. Ultrafiltration and post-HD diastolic blood pressure (DBP) increased from $2.36 \pm 0.91$ and $72.0 \pm 5.53$ to $2.51 \pm 0.87 \mathrm{~L}$ and $72.8 \pm 5.43$ $\mathrm{mmHg}$ respectively $(\mathrm{p}<0.01)$ (Table 1$)$.

The following data were obtained: hemoglobin A1c (HbA1c) levels increased from $5.94 \pm 0.67 \%$ to $6.78 \pm 1.33 \%(p<0.01)$, serum albumin levels from $3.67 \pm 0.32$ to $3.70 \pm 0.29 \mathrm{~g} / \mathrm{dL}(\mathrm{p}<0.05)$, serum iron from $67.9 \pm 32.1$ to $76.7 \pm 34.5 \mathrm{mcg} / \mathrm{dL}(\mathrm{p}<0.01)$, serum bicarbonate levels from $22.8 \pm 2.8$ to $24.4 \pm 3.8 \mathrm{meq} / \mathrm{L}(\mathrm{p}<0.01$ ), serum ferritin from $366.3 \pm 139.3$ to $479.5 \pm 194.5 \mathrm{ng} / \mathrm{mL}(\mathrm{p}<0.01)$, transferrin saturation from $33.0 \pm 16.3 \%$ to $37.3 \pm 17.6 \%(p<0.01), K t / V$ from $1.64 \pm 0.23$ to $1.69 \pm 0.35(p<0.01)$ (Table 2).

Pre-HD serum creatinine levels decreased from $7.09 \pm 2.03$ to $6.93 \pm 1.88$ $\mathrm{mg} / \mathrm{dL}(\mathrm{p}<0.05)$, serum total protein levels from $6.66 \pm 0.47$ to $6.59 \pm 0.44$ $\mathrm{g} / \mathrm{dL}(\mathrm{p}<0.01)$, serum uric acid levels from $5.96 \pm 1.11$ to $5.54 \pm 1.00 \mathrm{mg} / \mathrm{dL}$ $(p<0.01)$, CRP from $18.9 \pm 26.4$ to $12.9 \pm 19.2 \mathrm{mg} / \mathrm{L}(\mathrm{p}<0.01)$, and alkaline phosphatase from $154.5 \pm 116.7$ to $145.4 \pm 96.6 \mathrm{U} / \mathrm{L}(\mathrm{p}<0.05)$ (Table 2$)$.

Intradialytic complications of hypotension and muscle cramps decreased significantly $(0.075 \%$ to $0.043 \%, p<0.001$ and $0.016 \%$ to $0.008 \%, p<0.05$, respectively), whereas no increase in hypoglycemia was noted (Figure 1).

\section{Discussion}

Volume balance is the cardinal issue in the dialysis population. Cardiac diseases, mostly left atrial dilatation and left ventricular hypertrophy, are the leading causes of mortality among patients on HD. In our previous study, a total of 431 patients with prevalent HD were followed

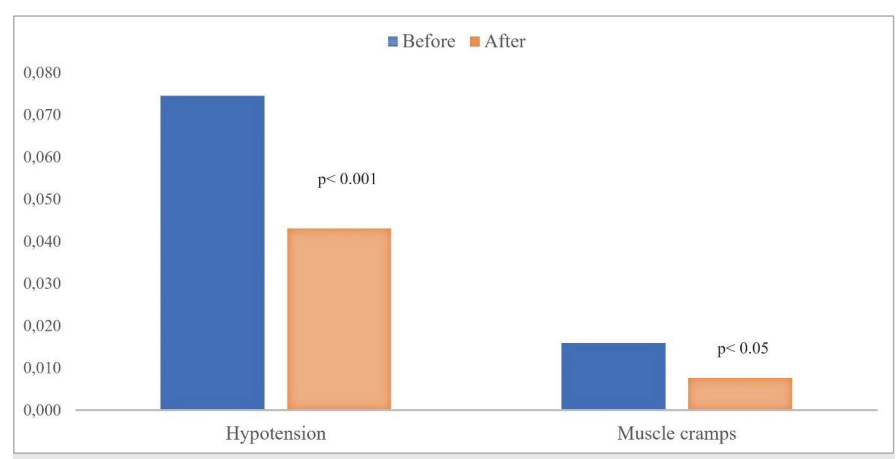

Figure 1. Intradialytic complications ( $p$-value, results of $\chi^{2}$ test) 


\section{Table 1. Hemodynamic parameters}

\begin{tabular}{|l|l|l|l|}
\hline & Meal during session & Without meal during session \\
\hline & Mean \pm SD (min.-max.) & Mean \pm SD (min.-max.) \\
\hline Pre-HD body weight $(\mathrm{kg})$ & $72.3 \pm 15.05(39.4-132.3)$ & $72.2 \pm 15.04(38.5-131.0)$ \\
\hline Dry weight $(\mathrm{kg})$ & $69.6 \pm 14.66(38.3-125.5)$ & $69.3 \pm 14.52(36.0-124.0)$ \\
\hline Post-HD body weight $(\mathrm{kg})$ & $70.0 \pm 14.77(38.2-128.0)$ & $69.7 \pm 14.74(36.9-126.6)$ \\
\hline Ultrafiltration (L) & $2.36 \pm 0.91(0.07-5.00)$ & $2.51 \pm 0.87(0.23-5.33)$ \\
\hline Pre-HD SBP $(\mathrm{mmHg})$ & $130.0 \pm 13.14(87.8-181.1)$ & $129.5 \pm 12.9(98.9-168.9)$ \\
\hline Pre-HD DBP $(\mathrm{mmHg})$ & $75.6 \pm 4.67(56.7-90.0)$ & $76.1 \pm 6.4(61.1-141.2)$ \\
\hline Post-HD SBP $(\mathrm{mmHg})$ & $120.6 \pm 12.98(91.1-174.4)$ & $121.8 \pm 12.7(94.4-172.2)$ \\
\hline Post-HD DBP $(\mathrm{mmHg})$ & $72.0 \pm 5.53(58.9-83.3)$ & $\mathbf{0 . 0 3 9 ^ { + }}$ \\
\hline +Paired samples t-test, SD: standard deviation, min.: minimum, max. maximum, HD: hemodialysis, SBP: systolic blood pressure, DBP: diastolic blood pressure & $0.002^{+}$ \\
\hline
\end{tabular}

prospectively, and hypervolemia and malnutrition were the long-term mortality indicators in patients on HD (11).

This study demonstrated that if consuming food or drinks is prevented during HD sessions, DBP, the hemodynamic parameter of post-HD, improves, facilitates sufficient ultrafiltration, and significantly decreases the dry weight. This provides adequate volume control chance, which is very important for these patients.

Although a study focused on increased albumin levels (12), in the present study, in addition to albumin, we detected increased $\mathrm{HbA} 1 \mathrm{C}$, serum iron, serum bicarbonate, serum ferritin, transferrin saturation, and Kt/V levels. This may be explained by the low interruption because of IDH episodes and the attainment of effective HD goals.

In the present study, levels of pre-HD serum creatinine, serum total protein, serum uric acid levels, CRP, and alkaline phosphatase decreased possibly because of fewer hypotension episodes, less tissue hypoxia, and inflammation.

Blood pressure is the product of cardiac output and vascular resistance. If any of these decreased and non-compensated by the other, hypotension would occur. During HD, plenty of blood circulates outside the body, causing decreased venous return and cardiac output, which finally results in hypotension. The reduction in myocardial contractility and heart rate in patients with cardiac disorders makes them vulnerable to IDH more than the normal population. This may explain how patients with blood volume decreases during HD are susceptible to hypotension problems.

The splanchnic region is very important for digestion. After meals, blood flows for the absorption of nutrients in the gastrointestinal system (13). Moreover, blood carries digestive enzymes to the target site. Studies have shown that postprandial celiac and superior mesenteric artery blood flow increased by $50-100 \%$ (14).

Experimental studies have shown that some vasoactive substances are secreted after consuming food, and pancreas perfusion increased in hyperglycemia and decreased in hypoglycemia (15). Blood flow is regulated by incretins in the splanchnic and systemic circulation (16).

Koffert et al. (17) demonstrated marked blood flow redistribution in the splanchnic vascular bed in response to a mixed meal because of direct chyme contact and elevations in the plasma levels of glucose and incretins, mainly glucose-dependent insulinotropic polypeptide (GIP). The putative vascular effects of glucagon-like peptide-1 and GIP are likely to be more potent during postprandial and hyperglycemic conditions (17).

Barakat et al. (18) examined the central hemodynamics of ten patients on dialysis who ingested a test meal $1 \mathrm{~h}$ into dialysis and were monitored by thoracic electric bioimpedance. They suggested that food ingestion during dialysis causes hypotension primarily because of decreased systemic vascular resistance (18).

According to the literature, Sherman et al. (19) analyzed postprandial blood pressure changes during HD. They found that 45 min after an intradialytic meal, the mean blood pressure dropped at $14.4 \mathrm{mmHg} / \mathrm{h}$, significantly more than the $2.2 \mathrm{mmHg} / \mathrm{h}$ decline in the control period. DBP also decreased more rapidly after eating. The mean weight loss values per session were 2.8 and $2.5 \mathrm{~kg}$ in the fasting and fed periods, respectively. However, this difference was attributed to the $0.3-\mathrm{kg}$ weight of the food. Similarly, the difference in weight loss was 0.82 $\mathrm{kg} / \mathrm{h}$ in the fasting period and $0.73 \mathrm{~kg} / \mathrm{h}$ in the feed period. The mean post-treatment weight was $0.23 \mathrm{~kg}$ greater in the fed period than in the fasting period. This difference could be also explained by the weight of the meal. Thirteen episodes of symptomatic hypotension were recorded in the 45-min postprandial intradialytic period compared with the two episodes during the corresponding control (fasting) period. Five of the nine patients experienced postprandial symptomatic hypotension during dialysis compared with 1 of 9 in the control period (19). Similar to the literature, the dry weight decreased from 69.6 to $69.3 \mathrm{~kg}$, and the post-HD bodyweight decreased from 70.0 to $69.7 \mathrm{~kg}$, ultrafiltration increased from 2.36 to $2.51 \mathrm{~L}$, and post-HD DBP increased from 72 to $72.8 \mathrm{mmHg}$. Moreover, intradialytic complications of hypotension and muscle cramps were both decreased significantly, whereas no increase in hypoglycemia was noted.

\section{Study Limitations}

This study retrospectively collected data from the medical records of the patients. Prospective randomized controlled trials may be conducted in the future. In this study, we performed HD sessions every 3 months with or without meals. Longer and more comprehensive studies in the future may provide additional data. The study was performed at a few HD centers. Further studies may be performed in several HD centers 
Table 2. Laboratory findings

\begin{tabular}{|c|c|c|c|}
\hline & Meal during session & Without meal during session & \\
\hline & Mean \pm SD (min.-max.) & Mean \pm SD (min.-max.) & $\mathbf{p}$ \\
\hline $\mathrm{WBC}\left(/ \mathrm{mm}^{3}\right)$ & $7.15 \pm 2.03(3.40-16.75)$ & $6.93 \pm 1.97(2.67-15.87)$ & $0.020^{+}$ \\
\hline $\mathrm{Hgb}(\mathrm{g} / \mathrm{dL})$ & $11.3 \pm 1.1(7.6-13.8)$ & $11.2 \pm 1.1(7.9-14.6)$ & $0.311^{*}$ \\
\hline HCT (\%) & $35.4 \pm 3.4(24.0-45.5)$ & $35.3 \pm 3.5(24.7-44.3)$ & $0.497^{*}$ \\
\hline MPV (fL) & $0.23 \pm 0.07(0.07-0.59)$ & $6.85 \pm 1.70(3.33-9.41)$ & $0.001^{*}$ \\
\hline $\mathrm{MCV}(\mathrm{fL})$ & $93.8 \pm 6.3(66.0-111.0)$ & $94.9 \pm 6.4(65.7-111.3)$ & $0.001^{*}$ \\
\hline $\mathrm{MCH}(\mathrm{pg})$ & $29.9 \pm 2.1(19.4-35.6)$ & $30.2 \pm 2.2(19.9-35.6)$ & $0.001^{*}$ \\
\hline HbA1c (\%) & $5.94 \pm 0.67(4.70-7.10)$ & $6.78 \pm 1.33(4.60-10.10)$ & $0.001^{+}$ \\
\hline Creatinine post-HD (mg/dL) & $2.32 \pm 0.80(0.90-6.42)$ & $2.27 \pm 0.74(0.89-6.01)$ & $0.064^{*}$ \\
\hline Potassium pre-HD (mg/dL) & $4.89 \pm 0.56(3.31-6.33)$ & $4.94 \pm 0.57(3.30-7.45)$ & $0.170^{+}$ \\
\hline Potassium post-HD (mg/dL) & $3.33 \pm 0.29(2.60-4.58)$ & $3.42 \pm 0.30(2.71-4.39)$ & $0.001^{*}$ \\
\hline $\mathrm{Kt} / \mathrm{V}$ & $1.64 \pm 0.23(1.06-2.63)$ & $1.69 \pm 0.35(0.90-3.36)$ & $0.042^{*}$ \\
\hline Urea reduction rate (\%) & $73.8 \pm 4.7(58.7-87.6)$ & $73.8 \pm 5.1(50.9-87.4)$ & $0.800^{+}$ \\
\hline Sodium (mg/dL) & $136.2 \pm 2.3(127.7-142.0)$ & $136.5 \pm 2.3(126.7-141.3)$ & $0.010^{+}$ \\
\hline Calcium (mg/dL) & $8.60 \pm 0.55(7.24-10.54)$ & $8.62 \pm 0.52(7.18-10.27)$ & $0.520^{+}$ \\
\hline Corrected calcium (mg/dL) & $8.88 \pm 0.55(7.34-10.65)$ & $8.88 \pm 0.52(7.18-10.34)$ & $0.990^{+}$ \\
\hline Total cholesterol (mg/dL) & $154 \pm 34(78-307)$ & $151 \pm 37(73-318)$ & NS \\
\hline LDL-cholesterol (mg/dL) & $82 \pm 27(27-176)$ & $84 \pm 26(28-199)$ & NS \\
\hline HDL-cholesterol (mg/dL) & $43 \pm 10(21-72)$ & $40 \pm 9(18-69)$ & NS \\
\hline Triglyceride (mg/dL) & $156 \pm 103(44-633)$ & $151 \pm 103(45-648)$ & NS \\
\hline Serum iron (mcg/dL) & $67.9 \pm 32.1(7.0-206.0)$ & $76.7 \pm 34.5(19.0-191.0)$ & $0.005^{*}$ \\
\hline $\mathrm{SIBC}(\mathrm{mcg} / \mathrm{dL})$ & $211.1 \pm 40.6(112.0-338.0)$ & $210.5 \pm 35.0(136.0-389.0)$ & $0.946^{*}$ \\
\hline Ferritin (ng/mL) & $366.3 \pm 139.3(39.0-1197.0)$ & $479.5 \pm 194.5(7.0-802.0)$ & $0.001^{*}$ \\
\hline TS (\%) & $33.0 \pm 16.3(4.0-92.0)$ & $37.3 \pm 17.6(8.0-91.0)$ & $0.005^{*}$ \\
\hline Uric acid (mg/dL) & $5.96 \pm 1.11(2.60-9.40)$ & $5.54 \pm 1.00(1.60-8.10)$ & $0.001^{+}$ \\
\hline CRP (mg/L) & $18.9 \pm 26.4(0.3-149.3)$ & $12.9 \pm 19.2(0.4-155.3)$ & $0.001^{*}$ \\
\hline Bicarbonate (meq/L) & $22.8 \pm 2.8(14.0-31.0)$ & $24.4 \pm 3.8(10.0-35.0)$ & $0.001^{*}$ \\
\hline $\operatorname{ALP}(\mathrm{U} / \mathrm{L})$ & $154.5 \pm 116.7(56.0-1308.0)$ & $145.4 \pm 96.6(55.0-857.0)$ & $0.045^{*}$ \\
\hline PTH (pg/dL) & $364.4 \pm 320.5(5.0-1671.0)$ & $326.4 \pm 282.8(1.0-1390.0)$ & $0.418^{*}$ \\
\hline
\end{tabular}


with patients who have diverse dietary habits. In this study, we analyzed albumin and lipid levels for nutritional status. In further studies, anthropometric measurements and bioimpedance spectroscopy may also be performed.

\section{Conclusion}

This study analyzed whether feeding or fasting during HD treatment would be beneficial for patients on HD. Eating during treatment may be beneficial for providing protein and calorie supplementation; however, eating may cause insufficient HD application because of intradialytic hemodynamic imbalance and complications, especially hypotension and cramps. This negatively affects the adequacy of the patient's HD treatment and increases mortality and morbidity in the long term. IDH and muscle cramps, which are mostly attributed to the splanchnic vasodilatation-related digestion process, may be prevented by restriction of food intake during HD sessions. Finally, in view of these results and those of related studies, it may be practical not to give food during HD sessions, despite the nutritional benefits for most patients.

Acknowledgement: The authors specially thank Dr. Naki Gökhan Turan, Dr. Ali Tunç, and Dr. Ahmet Sivri and nurses Ümmü Gülsüm Yolbaş, Ece Kaptan Tașdemir, and Fatma Çerçioğlu for their kind support.

Ethics Committee Approval: The approval form the University of Health Sciences Turkey, İstanbul Training and Research Hospital Local Ethics Committee was obtained (approval number: 2998, date: 24.12.2021).

Informed Consent: Informed consent was obtained from patients for the use of clinical information and results.

Peer-review: Externally peer-reviewed.

Authorship Contributions: Concept - \$..K., E.H.; Design - \$..K., E.H., H.Ç., S.D.; Data Collection or Processing - S..K., E.H., H.Ç., G.A., B.A., S.D.; Analysis or Interpretation - \$..K., E.H., H.Ç., G.A., B.A., S.D.; Literature Search - S..K., E.H., H.Ç., G.A., B.A., S.D.; Writing - \$̧.K., E.H., H.Ç., G.A., B.A., S.D.

Conflict of Interest: No conflict of interest was declared by the authors.

Financial Disclosure: The authors declared that this study received no financial support.

\section{References}

1. Flythe JE, Xue H, Lynch KE, Curhan GC, Brunelli SM. Association of mortality risk with various definitions of intradialytic hypotension. J Am Soc Nephrol 2015; 26: 724-34.

2. Sars B, van der Sande FM, Kooman JP, Intradialytic Hypotension: Mechanisms and Outcome. Blood Purif 2020; 49: 158-67.

3. Shoji T, Tsubakihara Y, Fujii M, Imai E. Hemodialysis-associated hypotension as an independent risk factor for two-year mortality in hemodialysis patients. Kidney Int 2004; 66: 1212-20.

4. Kuipers J, Verboom LM, Ipema KJ, Paans W, Krijnen WP, Gaillard CA, et al. The prevalence of intradialytic hypotension in patients on conventional hemodialysis A systematic review with meta-analysis. Am J Nephrol 2019; 49: 497-506.
5. Ma J, Pilichiewicz AN, Feinle-Bisset C, Wishart JM, Jones KL, Horowitz $\mathrm{M}$, et al. Effects of variations in duodenal glucose load on glycaemic, insulin, and incretin responses in type 2 diabetes. Diabet Med 2012; 29: 604-8.

6. Mano T, Iwase S. Sympathetic nerve activity in hypotension and orthostatic intolerance. Acta Physiol Scand 2003; 177: 359-65.

7. Ferrari AU. Modifications of the cardiovascular system with aging Am J Geriatr Cardiol 2002; 11: 30-3.

8. Purewal TS, Goss DE, Zanone MM, Edmonds ME, Watkins PJ. The splanchnic circulation and postural hypotension in diabetic autonomic neuropathy. Diabet Med 1995; 12: 513-22.

9. Rossi P, Andriesse GI, Oey PL, Wiemeke GH, Roelofs JM, Akkermans. Stomach distension increases efferent muscle sympathetic nerve activity and blood pressure in healthy humans. J Neurol Sci 1998; 161: 148-55.

10. Flythe JE, Xue H, Lynch KE, Curhan GC, Brunelli SM. Association of mortality risk with various definitions of intradialytic hypotension. J Am Soc Nephrol 2015; 26: 724-34.

11. Hür E, Köse \$, Mağden K, Yildiz G, Soyaltin U, Toka B, et al. The Relationship Between Bioimpedance-Measured Volume and Nutritional Parameters and Mortality in Hemodialysis Patients. Turkish J Nephrol 2017; 26: 183-9.

12. Jelicic I. Relationship of a food intake during hemodialysis and symptomatic intradialytic hypotension. Hemodial Int. 2021 Mar 10. https://doi.org/10.1111/hdi.12923

13. Matheson PJ, Wilson MA, Garrison RN. Garrison RN. Regulation of intestinal blood flow. J Surg Res 2000; 93: 182-96.

14. Someya N, Endo MY, Fukuda Y, Hayashi N. Blood flow responses in celiac and superior mesenteric arteries in the initial phase of digestion. Am J Physiol Regul Integr Comp Physiol 2008; 294: R17906.

15. Premen AJ. Kvietys PR. Granger DN. Postprandial regulation of intestinal blood flow: role of gastrointestinal hormones. Am J Physiol 1985; 249: G250-5.

16. Jansson L, Andersson A, Bodin B, Kallskog O. Pancreatic islet blood flow during euglycaemic, hyperinsulinaemic clamp in anesthetized rats. Acta Physiol (Oxf) 2007; 189: 319-24.

17. Koffert J, Honka H, Teuho J, Kauhanen S, Hurme S, Parkkola R, et al. Effects of meal and incretins in the regulation of splanchnic blood flow. Endocr Connect 2017; 6: 179-87.

18. Barakat MM, Nawab ZM, Yu AW, Lau AH, Ing TS, Daugirdas JT. Hemodynamic effects of intradialytic food ingestion and the effects of caffeine. J Am Soc Nephrol 1993; 3: 1813-8.

19. Sherman RA, Torres F, Cody RP. Postprandial blood pressure changes during hemodialysis. Am J Kidney Dis 1988; 12: 37-9. 